\title{
Ensino de Programação para Alunas de Ensino Médio: Relato de uma Experiência
}

\author{
Nadja Ramos ${ }^{1}$, Carmen Freitas ${ }^{2}$, Sandra Avila ${ }^{1}$, \\ Paula D. Paro Costa ${ }^{1}$, Vanessa Testoni ${ }^{3}$, Juliana Freitag Borin ${ }^{4}$ \\ ${ }^{1}$ Faculdade de Engenharia Elétrica e de Computação, \\ Universidade Estadual de Campinas (Unicamp), Campinas - SP - Brasil \\ ${ }^{2}$ Diretoria Geral de Recursos Humanos, \\ Universidade Estadual de Campinas (Unicamp), Campinas - SP - Brasil \\ ${ }^{3}$ Samsung Instituto de Pesquisa, Campinas - SP - Brasil \\ ${ }^{4}$ Instituto de Computação, \\ Universidade Estadual de Campinas (Unicamp), Campinas - SP - Brasil \\ nadjayanna@fee.unicamp.br, carmen.freitas@gmail.com,
sandra@dca.fee.unicamp.br, paula@dca.fee.unicamp.br,
vanessa.tesamsung.com, julianalic.unicamp.br
}

Abstract. This paper describes an experience conducted with high school girls, at Campinas, in order to bring them closer to computer science and technology areas. To attract the interest and hold the attention of young girls, the project was developed around the theme of building applications for smartphones. As a development platform, we used the MIT App Inventor educational tool to create Android applications. The applied methodology, the challenges, and the achieved results are reported to make possible the improvement and the replication of this experience.

Resumo. Este artigo descreve uma experiência realizada com alunas de ensino médio de uma escola pública estadual de Campinas, com o objetivo de aproximá-las da área de computação e do desenvolvimento de tecnologia. Para atrair o interesse e aproximar o projeto deste público jovem, o projeto foi desenvolvido em torno da temática da criação de aplicativos para smartphones. Como ferramenta de trabalho, utilizou-se a plataforma educacional MIT App Inventor de desenvolvimento de aplicativos Android. A metodologia aplicada, as dificuldades encontradas e os resultados alcançados são descritos no presente trabalho de modo que a experiência possa ser aprimorada e replicada.

\section{Introdução}

O baixo número de mulheres nas áreas de Exatas, Engenharias e Computação tem sido objeto de estudo no meio acadêmico [Hill et al. 2010, Coger et al. 2012, DuBow et al. 2013, Frieze and Quesenberry 2013] e de discussão na mídia em geral [Miller 2014, Tsukayama 2014, Rampell 2015]. Em contrapartida, diversas iniciativas estão sendo desenvolvidas com o objetivo de aumentar o interesse do público fe- 
minino por essas áreas, entre elas: Girls Who Code ${ }^{1}$, Sally Ride Science ${ }^{2}$, PyLadies $^{3}$, Meninas Digitais ${ }^{4}$, Technovation Challenge ${ }^{5}$, e os projetos desenvolvidos por Balieiro et al [Balieiro et al. 2014] e Bim [Bim 2011].

De acordo com Klawe, Whitney e Simard [Klawe et al. 2009], iniciativas de sucesso realizadas para meninas no ambiente pré-universitário envolvem atividades que permitem o contato com mulheres de sucesso na área, derrubam mitos e estereótipos associados às carreiras de computação e tecnologia, proveem informações precisas sobre a área para pessoas que exercem grande influência sobre as meninas (por exemplo, pais e professores), desenvolvem atividades práticas apropriadas para a idade, utilizam o potencial de impacto da tecnologia como forma de motivação, e promovem o engajamento de alunas e professores universitários em trabalhos com escolas de ensino fundamental e médio.

O projeto Android Smart Girls surgiu com o objetivo de estimular meninas do ensino médio a considerarem as carreiras de ciências exatas, engenharias e, em especial, computação como opções atrativas para seu futuro, bem como incentivar aquelas que já optaram por cursos de graduação nestas áreas a continuarem na carreira escolhida. De modo mais específico a execução deste projeto teve como expectativa:

- Proporcionar a alunas de ensino médio um primeiro contato prazeroso com noções de lógica de programação. Este primeiro contato deve ser feito de forma que elas percebam que programar pode ser algo estimulante e possível, não tão difícil quanto elas imaginavam;

- Possibilitar a alunas de ensino médio maior aproximação com o computador como instrumento de trabalho e noções básicas de funcionamento de smartphones estimulando-as a se interessar não só por cursos como ciência da computação, mas também por cursos das áreas de engenharia, por exemplo;

- Proporcionar a alunas de ensino médio a possibilidade de criar aplicativos de sua livre escolha para um dispositivo amplamente adotado pelos jovens em geral, o smartphone. Desta forma, acreditamos que as meninas estarão muito mais motivadas em aprender a desenvolver aplicativos que poderão ser exibidos orgulhosamente para amigos e familiares;

- Divulgar as carreiras de ciências exatas, engenharias e, em especial, computação, bem como desfazer possíveis mitos e estereótipos associados a essas carreiras não só entre as meninas diretamente envolvidas no projeto, mas também entre todos os alunos e professores de ensino médio da instituição co-executora;

- Proporcionar às alunas de graduação envolvidas no projeto a possibilidade de aplicar os conhecimentos já adquiridos na universidade em um projeto de importante impacto para a comunidade e uma escola, a curto prazo, e para a sociedade em geral, a longo prazo, de modo a estimulá-las a continuar seus estudos e perseguir a carreira escolhida;

- Incentivar as alunas de graduação a serem agentes multiplicadoras e motivadoras entre suas colegas de graduação;

\footnotetext{
${ }^{1}$ girlswhocode.com

${ }^{2}$ sallyridescience.com

${ }^{3}$ brasil.pyladies.com

${ }^{4}$ sbcmt.wordpress.com/meninasdigitais

${ }^{5}$ www.technovationchallenge.org
} 
- Avaliar se o ensino de programação tem impacto positivo no desempenho das meninas na escola e nas suas escolhas para a carreira futura.

O Android Smart Girls é fruto de uma parceria entre o grupo IEEE de Mulheres na Engenharia (Women in Engineering - WIE) da Unicamp (seção Sul Brasil) e o Instituto de Computação da Unicamp. O projeto, aprovado na chamada "MCTI/CNPq/SPMPR/Petrobras - Meninas e Jovens Fazendo Ciências Exatas, Engenharias e Computação" e apoiado pela Samsung, foi executado durante o ano de 2014 em uma escola estadual de ensino médio em Campinas. O restante do artigo apresenta a metodologia empregada na execução do projeto (Seção 2), os resultados alcançados (Seção 3) e as considerações finais (Seção 4).

\section{Metodologia}

O projeto Android Smart Girls foi executado em uma escola estadual de ensino médio e teve como bolsistas um professor de Matemática da escola, uma aluna de graduação em Engenharia da Computação da Unicamp e quatro alunas da escola. Adicionalmente, diversos voluntários da Unicamp e de empresas de tecnologia da região atuaram no projeto.

A primeira atividade consistiu em uma palestra sobre o projeto para as alunas da escola. Após a palestra, criou-se uma lista com as alunas interessadas em participar e levantou-se a preferência de horários para as atividades previstas. A diretoria da escola, então, solicitou que as alunas interessadas apresentassem uma autorização de participação dos responsáveis.

A execução do projeto foi dividida em duas fases. A primeira fase consistiu em um curso de desenvolvimento de aplicativos móveis para a plataforma Android ${ }^{6}$. Entretanto, a forma de ensino não seguiu àquela utilizada nos cursos padronizados de desenvolvimento para Android, já que isso exigiria conhecimentos mais avançados de programação na linguagem Java. O desenvolvimento dos aplicativos foi realizado utilizando a ferramenta MIT App Inventor ${ }^{7}$, que foca exatamente na criação de aplicativos por quem não tem experiência em programação. O MIT App Inventor é uma plataforma de programação visual criada pela Google em parceria com o MIT (Massachussets Institute of Technology), na qual se pode criar um aplicativo para Android utilizando blocos lógicos de maneira simples e intuitiva. O curso teve duração de doze semanas com uma aula semanal de duas horas.

O material didático utilizado no curso foi criado respeitando-se principalmente o conhecimento e interesse de um aluno de ensino médio (adolescentes). Por isto foi elaborado de forma que cada capítulo subsidiasse o desenvolvimento de um aplicativo único a ser desenvolvido ao longo do curso teórico. O tema escolhido para o aplicativo foi a Copa no Brasil na intenção de tratar de um assunto cotidiano que despertasse o interesse das meninas e de seus familiares. O único requisito definido para o aplicativo, que denominamos como Copa Campinas, foi o de conter informações relevantes sobre a Copa aos moradores de Campinas, os detalhes sobre funcionalidades foram deixados livres na tentativa de estimular o pensamento criativo.

\footnotetext{
${ }^{6} \mathrm{http}: / / \mathrm{www}$. android.com/

${ }^{7}$ http://appinventor.mit.edu/
} 
Assim, cada capítulo do material didático foi estruturado em três partes: apresentação teórica de um novo componente da ferramenta App Inventor; explicação passo a passo para desenvolver uma funcionalidade simples utilizando o componente recém apresentado (desvinculado do aplicativo Copa Campinas), onde eram apresentados os blocos lógicos e conceitos de lógica de programação; e por último um enunciado com orientações gerais para incrementar funcionalidades no Copa Campinas considerando os novos conhecimentos adquiridos. O desenvolvimento foi sempre orientado pelos professores e monitores voluntários e ao final do curso teórico houve a apresentação dos aplicativos "Copa Campinas"desenvolvidos individualmente pelas meninas.

Na segunda fase do projeto, as alunas se reuniram em equipes com três integrantes com o objetivo de desenvolverem todo o processo de criação de um aplicativo: concepção da ideia, planejamento do aplicativo, implementação e apresentação do resultado final. Cada equipe teve o acompanhamento de duas mentoras, que são profissionais formadas, e atuaram como guias e modelos de conduta ao longo do desenvolvimento do aplicativo. Durante esta fase, que teve duração de quatro meses, foram realizados encontros quinzenais na escola. Estes encontros eram voltados para a interação entre alunas e mentoras, e incluiram palestras com foco em conceitos não explorados durante o curso, tais como definição do público alvo do aplicativo, usabilidade, design de interação e experiência do usuário.

Os aplicativos desenvolvidos foram apresentados pelas equipes em um evento na escola. Um júri técnico avaliou as apresentações e fez a escolha da melhor equipe.

\section{Resultados}

Os resultados desta experiência podem ser divididos em três esferas principais: (1) a aquisição de conhecimento sobre o comportamento do público-alvo em relação ao uso da tecnologia (Seção 3.1); (2) a avaliação do impacto do projeto para as alunas que concluíram o curso (Seção 3.2); (3) o mapeamento dos pontos fortes e fracos do projeto visando melhorias para futuras edições do mesmo (Seção 3.3).

\subsection{Comportamento em Relação ao Uso da Tecnologia}

Uma das necessidades iniciais do projeto era o entendimento da realidade do públicoalvo do projeto em relação ao uso da tecnologia. Visando a aquisição de informações sobre este aspecto, durante a palestra de apresentação e de recrutamento para o projeto na escola, distribuiu-se um questionário às alunas presentes.

Além de uma questão sobre o ano do Ensino Médio que a aluna estava cursando (primeiro, segundo ou terceiro ano), o questionário continha quatro questões de múltipla escolha. O questionário foi respondido por 62 garotas, sendo: $42 \%$ do primeiro ano de ensino médio, $31 \%$ do segundo ano e $27 \%$ do último ano do ensino médio. A resposta aos questionários se deu de maneira anônima.

A primeira questão tratava sobre o uso de computador em casa. O texto da questão era: "Tem computador em casa? Com que frequência usa?". Como resposta à esta questão, $21 \%$ das garotas afirmaram não ter computador em casa; $34 \%$ afirmaram ter computador em casa mas utilizá-lo menos de três vezes por semana; $16 \%$ afirmaram utilizar o computador disponível em casa até quatro vezes semana e 29\% afirmaram utilizar o computador de casa mais de quatro vezes por semana. 
A segunda questão visava investigar que tipo de atividades as jovens faziam ao utilizarem um computador. Nesta questão, as alunas podiam assinalar mais de uma alternativa. Como resultado, obteve-se:

- $87 \%$ utilizam o computador para acessarem as redes sociais;

- $74 \%$ fazem trabalhos escolares no computador;

- $64 \%$ utilizam o computador para assistir filmes e ouvir música;

- $24 \%$ acessam seus e-mails pelo computador;

- $24 \%$ das alunas afirmaram realizar a leitura de blogs;

- $23 \%$ buscam informações sobre serviços;

- $14 \%$ utilizam o computador para troca de mensagens ("chat");

- $11 \%$ jogam jogos eletrônicos no computador;

- $6 \%$ realizam pesquisas de preço;

- 2 alunas (aprox. 3\%) afirmaram desenvolver programas de computador.

A terceira questão questionava as alunas se elas possuíam um "smartphone". As respostas possíveis eram: (a) "Sim", (b) "Não"e (c) "Não sei se o aparelho que possuo é um smartphone.". Quarenta e cinco porcento das alunas afirmaram possuir um "smartphone", 42\% afirmaram não possuir o aparelho e 13\% das alunas não souberam definir se o aparelho que possuem é um "smartphone".

Na última questão, as alunas eram questionadas sobre suas matérias escolares preferidas. As alunas podiam selecionar mais de uma disciplina. A disciplina de português foi assinalada por $53 \%$ das alunas, $40 \%$ das alunas assinalou "Matemática"como uma de suas matérias preferidas, $35 \%$ assinalaram a disciplina de biologia, seguida por artes $(25 \%)$, filosofia (24\%), educação física (23\%), história (21\%), inglês (19\%), química $(17 \%)$, geografia $(16 \%)$, sociologia $(12 \%)$ e, assinalada pela minoria como uma das matérias preferidas, física (8\%). Aproximadamente, $17 \%$ das alunas assinalaram nenhuma ou até duas disciplinas favoritas; $50 \%$ assinalou três disciplinas como favoritas e 33\% assinalaram mais de 4 disciplinas como favoritas.

A análise das respostas ao questionário permitem visualizar um cenário no qual a maioria das alunas faz uso frequente da tecnologia. Porém, os resultados denunciam que uma parcela importante ainda se encontra distante do cenário de acesso à informação e socialização por meio de computadores e/ou "smartphones".

Chama-se atenção também para a grande proporção de alunas que possuem a disciplina de "Matemática"como uma de suas disciplinas preferidas, característica que pode ser aproveitada para o futuro direcionamento para as carreiras de computação.

\subsection{Impacto do Projeto Para as Alunas Participantes}

Desde o início do projeto existiu a preocupação de se propor mecanismos de avaliação do impacto do curso para as alunas. Foram elaborados dois tipos de avaliação: uma avaliação de percepção pessoal e da carreira de engenharia de computação e uma avaliação de pensamento computacional. Ambas avaliações foram aplicadas no início do curso (no segundo encontro) e ao final do curso (no último encontro).

A avaliação de percepção pessoal e da carreira de engenharia de computação foi realizada por meio de um questionário com 44 questões. A maioria das questões exigia resposta de acordo com a escala de Likert, utilizando os termos: "Concordo Plenamente", 
"Concordo Parcialmente", "Não tenho opinião/Não sei", "Discordo Parcialmente", "Discordo Plenamente". As primeiras 11 questões do questionários visavam fornecer um entendimento sobre imagem que a estudante fazia de si mesma, de sua família e de seus colegas, fazendo-a opinar sobre afirmações como "Eu sou inteligente.", "Eu sou uma boa aluna.", "Para minha família, estudar é a responsabilidade mais importante de um jovem.", "Meus colegas (RAPAZES) me consideram boa aluna e me procuram para estudar, solucionar dúvidas ou para os trabalhos em grupo.". As questões restantes procuravam avaliar a percepção da aluna em relação à carreira de engenharia ou ciência da computação, solicitando a opinião da jovem sobre afirmações como: "Um curso superior de computação usa pouca matemática.", "Um curso superior de computação ensina a usar software.", "Um curso superior de computação é fácil para quem já sabe usar o computador.", "Trabalhar em computação paga bem.".

A avaliação de pensamento computacional [Wing 2006] foi concebida como um conjunto de 6 problemas considerados simples e de fácil resolução pela equipe responsável pela condução do projeto e que tinha como principal objetivo avaliar as seguintes habilidades das jovens:

- Decomposição: a capacidade de quebrar um problema em partes;

- Reconhecimento de padrões: a capacidade de elaborar um modelo e colocá-lo em prática;

- Abstração: capacidade de generalização de um modelo;

- Definição de um algoritmo: capacidade de definir uma sequência de instruções para solução de um problema.

A avaliação foi projetada para ser realizada em 20 minutos, intervalo de tempo que verificou-se apropriado durante a aplicação das avaliações. A avaliação aplicada no início do curso continha questões diferentes da avaliação do final do curso, mas que procuraram abordar as mesmas habilidades.

A análise aprofundada do resultado de ambas avaliações tem sido objeto de pesquisa por parte da equipe que conduziu o projeto. Uma das dificuldades encontradas é o pequeno número de amostras que não permite a generalização das conclusões para uma população maior. No início do curso, das 22 alunas regularmente inscritas, apenas 17 estavam presentes no dia em que as avaliações foram aplicadas. Ao final do curso, das 9 alunas concluintes, apenas 6 alunas estavam presentes no dia em que as avaliações foram aplicadas.

Ainda sim, é possível traçar o seguinte perfil das estudantes:

- As garotas participantes do curso se consideravam boas alunas e capazes de alcançar bons resultados intelectuais;

- Elas percebem o apoio e o valor que a família dá aos estudos;

- As estudantes consideram, na mesma proporção, que seu futuro profissional pode se dar tanto como empregadas do setor privado quanto como proprietárias do próprio negócio;

- Elas têm uma visão pouco clara do que é um curso na área de computação e várias delas não souberam opinar sobre diferentes afirmações relacionadas à área da computação.

Pôde-se observar um grau de esclarecimento maior sobre a profissão de engenharia e ciência da computação ao final do curso. A realização de aulas e palestras com 
profissionais da área certamente contribuiu para esse resultado, como apresentado na seção seguinte.

Uma das hipóteses iniciais do projeto era que as participantes do curso apresentariam uma melhoria em suas habilidades de pensamento computacional após a realização do curso. No entanto, isso não pôde ser verificado de maneira objetiva. As alunas tiveram um desempenho semelhante tanto na avaliação do início do curso quanto na avaliação aplicada ao final do projeto. Mais de $60 \%$ das alunas acertou menos de $50 \%$ das questões da avaliação, considerado pela equipe como um desempenho ruim, já que os problemas eram considerados fáceis. É importante ressaltar que, atualmente, inexistem metodologias universalmente aceitas para a avaliação objetiva das habilidades de pensamento computacional. A validação formal da metodologia de avaliação proposta é uma das áreas de pesquisa alavancadas por este projeto.

\subsection{Avaliação do Projeto}

Uma primeira avaliação do projeto pôde ser realizada por meio da análise das listas de presença de cada aula do curso.

O gráfico da Figura 1 mostra o número de alunas presentes a cada aula do curso e durante toda a segunda fase do projeto, após a formação dos grupos e início da criação do aplicativo final. É possível observar uma queda significativa no número de alunas frequentando as aulas no início do curso e ao final do mesmo. De 22 ingressantes, 9 garotas concluíram o curso.

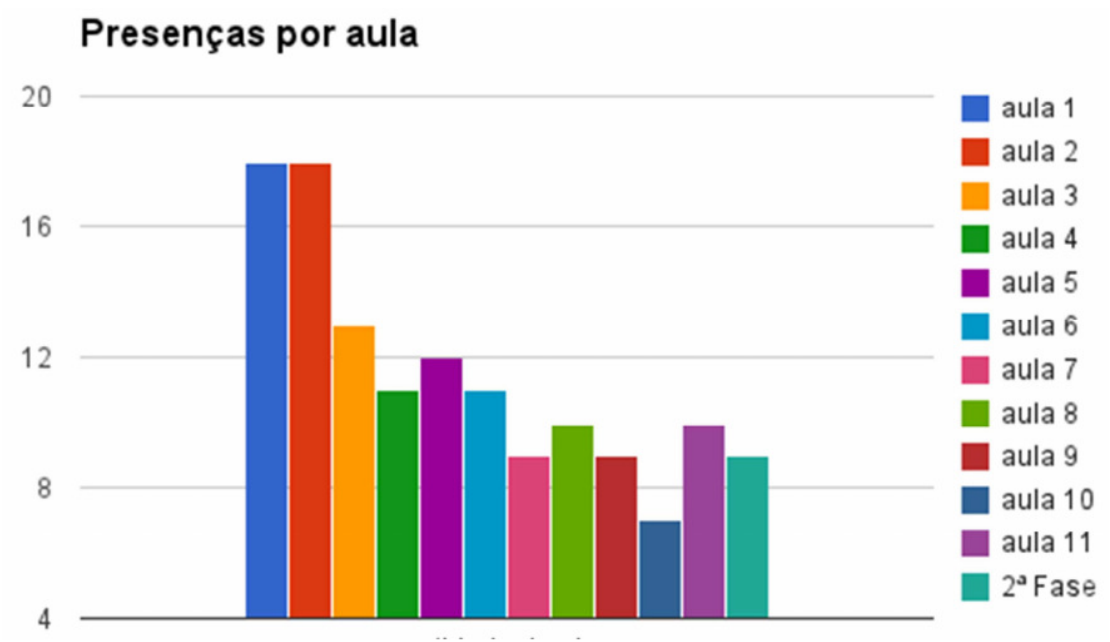

Figura 1. Frequência das alunas durante a primeira fase (aulas) e a segunda fase (palestras e desenvolvimento do aplicativo) do projeto Android Smart Girls.

A análise dos diários de classe e entrevistas com as desistentes revelou possíveis motivos para a evasão acentuada nas primeiras aulas do projeto:

- As primeiras aulas do projeto foram seriamente prejudicadas por problemas de infra-estrutura no laboratório de informática da escola. Problemas relacionados à instalação de software pela equipe responsável na escola e falta de acesso à Internet, não permitiram que as alunas tivessem uma visão clara das possibilidades oferecidas pelo curso. 
- O caráter extra-curricular, em horário noturno, parece ter desestimulado alunas e suas famílias.

- Dificuldades na compreensão de conceitos e componentes em inglês.

- Falta de familiaridade com computadores ou smartphones.

Ao final do curso, seis alunas concluintes também preencheram um formulário onde elas poderiam comentar de maneira livre e anônima três tópicos: o que elas mais gostaram do projeto, o que elas não gostaram do projeto e o que elas gostariam que mudasse em outra edição do projeto.

Ao relatarem o que elas mais gostaram do projeto, um comentário foi unânime entre todas as alunas: a interação com os mentores e as palestras foram fortemente elogiadas. Várias delas relataram que os mentores demonstravam grande esforço para fazer com elas alcançassem os objetivos estabelecidos e que os palestrantes traziam assuntos que elas consideravam relevantes para seu futuro.

Quanto ao que elas não gostaram do projeto, as principais reclamações foram: a dificuldade em implementar ideias mais elaboradas e complexas utilizando a plataforma MIT App Inventor, a estrutura ruim do laboratório de informática da escola o que, para algumas alunas, foi interpretado como falta de interesse da escola no projeto.

Quanto ao que poderia ser melhorado em relação ao projeto as principais sugestões foram: que mais alunas participassem, que a organização do curso fosse melhorada e que elas pudessem votar o tema dos aplicativos na primeira parte do curso.

Abaixo seguem alguns comentários extraídos deste formulário:

- "Os voluntários são ótimos. O projeto realmente me ensinou a montar um aplicativo. Gostei muito das palestras, sempre trazendo pessoas diferentes e dava para perceber que elas realmente estavam gostando do nosso projeto e elas tinham vontade de ajudar e ajudaram."

- "Não gostei do App Inventor, ele nos atrapalhou muito na criação dos aplicativos, pois ele é limitado."

- "Deveria também haver mais opções de programação além do App Inventor pois assim ficamos muito restritas. O projeto deveria também ser aberto para mais meninas. E as meninas da primeira edição devem participar nas próximas."

- "Queria que o projeto tivesse durado mais tempo!"

\section{Considerações Finais}

No mundo onde se discute a crise dos modelos tradicionais de Educação, fazer com que jovens dinâmicos, ansiosos e fortemente conectados se sintam motivados com o modelo de ensino sequencial e segmentado tipicamente observado nas escolas parece ser um grande desafio. O desafio pode ser considerado ainda maior se considerarmos a precariedade das escolas públicas que é frequentemente evidenciado na realidade brasileira.

Uma das grandes conquistas deste projeto parece ser ter conseguido fazer com essas jovens se engajassem com seriedade num objetivo comum e lamentassem não poder continuar seu aprendizado ao término do curso.

Se por um lado este é um forte incentivo para que iniciativas como essa sejam replicadas, por outro mostra-se importante buscar o aprimoramento do modelo implementado. 
A partir da análise dos resultados do projeto, a replicação futura deste projeto deve considerar os seguintes aprendizados:

- Problemas técnicos foram um fator importante na desmotivação das alunas. É importante garantir infra-estrutura mínima funcional durante todo o andamento do curso, que deve ser composta, idealmente, por um computador por aluna que atenda aos pré-requisitos de performance exigidos pelo MIT App Inventor e acesso à Internet de qualidade.

- Deve-se buscar a minimização das barreiras impostas pela interface disponível apenas na língua inglesa, seja através de aulas dedicadas a sanar tais dificuldades no contexto do curso ou através da adaptação e tradução da Interface.

- Deve-se buscar pontes que possibilitem migrar da fase de atração para a atividade de programação para a fase de aprendizado mais aprofundado, eventualmente migrando-se da plataforma em blocos funcionais (MIT App Inventor) para linguagens e/ou ambientes menos limitados.

- A convivência com profissionais do mercado de computação foi um dos pontos mais elogiados por todas as participantes do curso. Deve-se investir em palestras e oportunidades de troca de experiências das alunas com estes(as) profissionais. incluem:

Por último, é importante destacar trabalhos futuros decorrentes deste projeto que

- a documentação e a confecção de um relatório detalhado das avaliações propostas e seus resultados;

- a compilação e a disponibilização pública do material didático em português criado para este projeto;

- a criação de um manual com orientações e diretrizes para a reprodução deste tipo de iniciativa em outras localidades por outras equipes mentoras.

\section{Agradecimentos}

As autoras agradecem ao suporte financeiro do MCTI/CNPq/SPM-PR/Petrobras (processo 420195/2013-0), ao apoio da Samsung Eletrônica da Amazônia LTDA., ao apoio da Escola Estadual Professor Hilton Federici, ao Prof. Eduardo Valle (FEEC/Unicamp) pela contribuição na coleta de resultados e a todos os voluntários envolvidos no projeto.

\section{Referências}

Balieiro, K. M., Cosme, L. B., da Silva, A. M., Cangussu, A. C. M., and Cosme, L. B. (2014). Inclusão Digital de Mulheres no IFNMG Campus Montes Claros: Um Relato de Experiência. In XXII Workshop sobre Educação em Informática.

Bim, S. A. (2011). Uma experiência de ensino de interação humano-computador para alunas do ensino médio. In XIX Workshop sobre Educação em Informática.

Coger, R., Cuny, J., Klawe, M., McGann, M., and Purcell, K. (2012). Why STEM fields still don't draw more women. The Chronicle of Higher Education. Disponível em: http://chronicle.com/article/Why-STEM-Fields-Still-Dont/135302/.

DuBow, W. M., Farmer, R., Wu, Z., and Fredrickson, M. (2013). Bringing young women into computing through the ncwit aspirations in computing program. Commun. ACM, 56(12):34-37. 
Frieze, C. and Quesenberry, J. L. (2013). From difference to diversity: Including women in the changing face of computing. In Proceeding of the 44th ACM Technical Symposium on Computer Science Education, SIGCSE '13, pages 445-450, New York, NY, USA. ACM.

Hill, C., Corbett, C., and Rose, A. (2010). Why so few? Women in Science, Technology, Engineering, and Mathematics. American Association of University Women (AAUW) Research Report. Disponível em: http://www.aauw.org/files/2010/03/WhySo-Few.pdf.

Klawe, M., Whitney, T., and Simard, C. (2009). Women in computing-take 2. Commun. ACM, 52(2):68-76.

Miller, C. C. (2014). Some universities crack code in drawing women to computer science. New York Times.

Rampell, C. (2015). Women falling behind in stem bachelor's degrees. The Washington Post.

Tsukayama, H. (2014). No, really. how do we get girls to code? The Wahington Post.

Wing, J. M. (2006). Computational thinking. Communications of the ACM, 49(3):33-35. 